\title{
INTERVENCIÓN ADMINISTRATIVA DE LOS ENTES DESCENTRALIZADOS EN LA PROVINCIA DE CORRIENTES, ARGENTINA
}

\author{
ADMINISTRATIVE INTERVENTION OF \\ DECENTRALIZED ENTITIES \\ IN THE PROVINCE OF CORRIENTES, \\ ARGENTINA
}

\section{MAURICIO GOLDFARB}

Facultad de Derecho y Ciencias Sociales y Políticas

Universidad Nacional del Nordeste

ARGENTINA

La vida es inherentemente arriesgada. Solo hay un riesgo mayor que deberías evitar, y es el riesgo de no hacer nada. 


\title{
RESUMEN
}

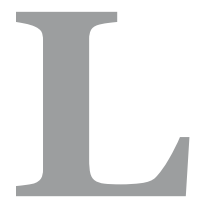

a intervención administrativa de los entes descentralizados es una forma de control excepcional sobre las entidades separadas de la administración central. Es una institución regulada constitucional y legalmente como un modo de reestablecer el normal funcionamiento de estos entes. En el presente artículo se expone el marco normativo de la intervención y se lo contrasta con la práctica y desarrollo de esta institución en la provincia de Corrientes en los últimos 25 años.

Palabras Clave: organización, acto administrativo, control, regulación.

\begin{abstract}
Administrative intervention of the decentralized entities is an exceptional form of control over the separate entities of the central administration. It is a constitutional and legally regulated institution as a way to restore the normal functioning of these entities. In this article the regulatory framework of the intervention is exposed and contrasts it with the practice and development of this institution in the province of Corrientes in the last 25 years.
\end{abstract}

Keywords: administrative organization, administrative act, control, regulation.

\section{INTRODUCCIÓN}

El objeto de este trabajo de investigación es analizar críticamente la institución de la intervención administrativa de los entes descentralizados. Si bien la unidad de análisis es la provincia de Corrientes (Argentina), sus conclusiones son extensibles a otras jurisdicciones que adoptan el sistema de descentralización administrativa. ${ }^{1}$

El tema en discusión se vincula en forma directa con los principios de organización administrativa. Más allá de la necesaria fundamentación doctrinaria, el tema no se aborda desde una perspectiva puramente teórica, sino que se contrasta el marco constitucional y legal con la forma en la que, en la práctica, se ha desarrollado esta institución. 


\section{CENTRALIZACIÓN Y DESCENTRALIZACIÓN}

La doctrina administrativista nacional enseña que la Administración se organiza en base a los principios de jerarquía, competencia, centralización y descentralización Cassagne (1998); Dromi (2009); Balbín (2011); Gordillo (2009). El esquema piramidal (tradicional) de la Administración con base en los tres primeros principios ha aumentado su complejidad con la incorporación de los organismos descentralizados, dotados de una personalidad y patrimonio diferenciados de la administración centralizada.

Balbín (2011) destaca que la descentralización es una técnica de distribución de competencias que se distingue por el reconocimiento de personalidad jurídica a los entes estatales, de modo que el vínculo con el Ejecutivo es más distante y solo de control (no jerárquico).

La descentralización posee varias ventajas. En primer lugar, permite la constitución de entes altamente especializados en su materia (jubilaciones, servicios de salud, fomento de la actividad económica, etc.). Otra ventaja es la fragmentación del poder, que funciona como contrapeso de tendencias autoritarias que puedan existir en el poder ejecutivo. También son formas desarrolladas de participación democrática, ya que varios de ellos prevén la intervención de los ciudadanos en su gobierno. De este modo se cumple con la cláusula constitucional del artículo 42 de la Constitución Nacional $^{2}$ y del artículo 48 de la Constitución de la provincia de Corrientes ${ }^{3}$ en materia de participación de los usuarios, especialmente cuando se trata de organismos de control (p.e. Ente Regulador de Aguas).

Los entes descentralizados son personas de derecho público, estatales, creadas con el fin de satisfacer ciertos intereses públicos. En el caso de la provincia de Corrientes, el Código de Procedimientos Administrativos establece que hay descentralización "cuando el ordenamiento jurídico confiere en forma regular y permanente atribuciones a entidades dotadas de personalidad jurídica y patrimonio propio que actúan por orden y cuenta propia, bajo el control del Poder Ejecutivo en la forma y con los fines establecidos en la ley". ${ }^{4}$

\footnotetext{
${ }^{2}$ Constitución Nacional, artículo 42. Los consumidores y usuarios de bienes y servicios tienen derecho, en la relación de consumo, a la protección de su salud, seguridad e intereses económicos; a una información adecuada y veraz; a la libertad de elección, y a condiciones de trato equitativo y digno.

Las autoridades proveerán a la protección de esos derechos, a la educación para el consumo, a la defensa de la competencia contra toda forma de distorsión de los mercados, al control de los monopolios naturales y legales, al de la calidad y eficiencia de los servicios públicos, y a la constitución de asociaciones de consumidores y de usuarios.

La legislación establecerá procedimientos eficaces para la prevención y solución de conflictos, y los marcos regulatorios de los servicios públicos de competencia nacional, previendo la necesaria participación de las asociaciones de consumidores y usuarios y de las provincias interesadas, en los organismos de control.

${ }^{3}$ Constitución de la Provincia de Corrientes, artículo 48: Los consumidores y usuarios de bienes y servicios tienen derecho, en la relación de consumo, a la protección de su salud, seguridad e intereses económicos, a una información adecuada y veraz, a la libertad de elección y a condiciones de trato equitativo y digno. Las autoridades deben proveer a la protección de esos derechos, a la educación para el consumo, a la defensa de la competencia contra toda forma de distorsión de los mercados, al control de los monopolios naturales y legales, al de la calidad y eficiencia de los servicios públicos, y a la constitución de asociaciones de consumidores y usuarios. La legislación establece los marcos regulatorios de los servicios públicos de competencia provincial, previendo el mecanismo de audiencias públicas y la necesaria participación en los organismos de control y en la confección o modificación de dicho régimen regulatorio, de las asociaciones de consumidores y usuarios y de los municipios interesados. Toda persona tiene el derecho de elegir la vía de resolución para sus controversias, disputas o conflictos, que puede ser la conciliación, mediación, arbitraje o instancia judicial. En los casos donde el Estado provincial y las municipalidades sean parte de la controversia, se preferirá la vía arbitral. La ley establece las normas y procedimientos a cumplimentar en cada caso y las excepciones para cada una de las vías de resolución.

${ }^{4}$ Ley 3460, artículo 76.
} 
Tanto en el orden nacional como en el caso de la provincia de Corrientes, no existe un régimen jurídico único para la regulación de todos los entes descentralizados. Por el contrario, cada ente tiene prevista su regulación y competencias en las normas de creación.

Respecto de estos entes autárquicos y descentralizados, el Poder Ejecutivo no tiene más poder jerárquico que el control de la juridicidad de los actos. Se excluye así el control de oportunidad o mérito de su actividad, el que se delega por razones de mayor especialidad técnica. Dentro de este marco, la entidad descentralizada tiene poderes discrecionales que no pueden ser invadidos por la administración central (Dromi 2009, p.704).

Sin embargo, el Poder Ejecutivo no se desliga del accionar cotidiano de los entes. Así, el titular del ejecutivo mantiene las atribuciones de: 5

a) Dar instrucciones generales a la entidad;

b) Decidir en los recursos y denuncias que se interpongan contra sus actos en los casos previstos en la ley;

c) Intervenir por las causas y por el procedimiento establecido en la ley de procedimientos o en la ley de creación del ente;

d) Nombrar y remover a sus autoridades superiores en los plazos y condiciones previstas en el ordenamiento jurídico;

e) Realizar investigaciones preventivas.

Todas estas atribuciones son consecuencia del carácter estatal de los entes. Por ello, el gobernador, en su carácter de jefe máximo de la Administración, ${ }^{6}$ es siempre la mayor autoridad administrativa y es quien fija las políticas administrativas generales a la cual todas las entidades administrativas deben adecuarse (Dromi 2009, p.701). Gordillo (2009, TI, 4) subraya que existe una permanente oscilación entre la tendencia legislativa a liberar a los entes de los controles de la administración central y la inclinación del ejecutivo a someterlas a sus “controles de legalidad".

\section{LOS ENTES DESCENTRALIZADOS EN LA PROVINCIA DE CORRIENTES}

En la provincia de Corrientes, los entes descentralizados son muy importantes en número, competencias y presupuesto. Sin embargo, la investigación sobre esta materia es muy escasa, salvo el exhaustivo comentario que al respecto formularon los autores de la ley 3460.

De acuerdo a la ley de presupuesto de 2016, en la provincia existen 11 entes descentralizados, cuyas competencias incluyen tareas tan importantes como el otorgamiento y pago de los haberes previsionales (Instituto de Previsión Social - IPS), el sistema de salud de empleados y jubilados provinciales (Instituto de la Obra Social de Corrientes - IOSCOR), la provisión de energía eléctrica (Dirección Provincial de Energía - DPEC), la construcción de viviendas

\footnotetext{
${ }^{5}$ Ley 3460, artículo 78.

${ }^{6}$ Constitución de la Provincia de Corrientes, artículo 162 inciso 1.
} 
sociales (Instituto de Vivienda de Corrientes - INVICO), la gestión y control del juego (Instituto de Loterías y Casinos) y la construcción y mantenimiento de los caminos y rutas provinciales (Dirección Provincial de Vialidad - DPV) entre los más relevantes.

El cuadro completo de los entes descentralizados es el siguiente:

Tabla Nº1. Entes descentralizados de la provincia de Corrientes

\begin{tabular}{|c|c|c|c|}
\hline Nombre del Ente & Objeto & Norma de creación & Autoridades \\
\hline $\begin{array}{l}\text { Instituto de Previsión } \\
\text { Social }\end{array}$ & $\begin{array}{l}\text { Otorgamiento y pago de } \\
\text { haberes previsionales }\end{array}$ & $\begin{array}{c}\text { Leyes 389, 1112, } \\
2200,2980,3295 \text { y } \\
4917 \text { (vigente) }\end{array}$ & $\begin{array}{l}\text { Administrador General } \\
\text { y Directorio (4 vocales, } \\
2 \text { representantes del } \\
\text { Ejecutivo, } 1 \text { por el } \\
\text { personal activo y } 1 \text { por } \\
\text { el personal jubilado) }\end{array}$ \\
\hline $\begin{array}{l}\text { Instituto de Loterías y } \\
\text { Casinos }\end{array}$ & $\begin{array}{l}\text { Gestión del juego, } \\
\text { hoteles y casinos }\end{array}$ & $\begin{array}{l}\text { Ley } 3423 \text { y } \\
\text { modificatorias }\end{array}$ & $\begin{array}{c}\text { Presidente y Directorio } \\
\text { (4 vocales designados } \\
\text { por el Ejecutivo) }\end{array}$ \\
\hline $\begin{array}{l}\text { Dirección Provincial de } \\
\text { Energía }\end{array}$ & $\begin{array}{c}\text { Gestión del servicio } \\
\text { público de energía eléctrica }\end{array}$ & $\begin{array}{l}\text { Ley } 3588 \text { y } \\
\text { modificatorias }\end{array}$ & $\begin{array}{l}\text { Presidente y Directorio } \\
\quad \text { (4 vocales, } 3 \text { en } \\
\text { representación del } \\
\text { Ejecutivo } 3 \text { y } 1 \text { por los } \\
\text { trabajadores del ente) }\end{array}$ \\
\hline $\begin{array}{l}\text { Instituto de la Obra Social } \\
\text { de Corrientes }\end{array}$ & $\begin{array}{c}\text { Servicios de seguridad social y salud } \\
\text { para trabajadores de la administración } \\
\text { y sus grupos familiares }\end{array}$ & $\begin{array}{l}\text { Ley } 3341 \text { y } \\
\text { modificatorias }\end{array}$ & $\begin{array}{c}\text { Presidente y Directorio } \\
\text { (4 vocales designados } \\
\text { por el Ejecutivo) }\end{array}$ \\
\hline $\begin{array}{l}\text { Instituto de Vivienda de } \\
\text { Corrientes }\end{array}$ & Construcción de viviendas sociales & Ley 3411 & $\begin{array}{l}\text { Presidente y Directorio } \\
\text { (4 miembros) }\end{array}$ \\
\hline $\begin{array}{l}\text { Dirección Provincial de } \\
\text { Vialidad }\end{array}$ & $\begin{array}{c}\text { Construcción y reparación de vías de } \\
\text { comunicación terrestres }\end{array}$ & Ley 3288 & $\begin{array}{l}\text { Presidente y Directorio } \\
\text { (4 miembros) }\end{array}$ \\
\hline Ente Regulador de Aguas & $\begin{array}{l}\text { Control del concesionario } \\
\text { del servicio público de agua } \\
\text { potable y cloacas }\end{array}$ & $\begin{array}{c}\text { Ley } 3573 \text { y Decreto } \\
5121 / 90\end{array}$ & $\begin{array}{c}\text { Administrador General } \\
\text { y Consejo Directivo ( } 3 \\
\text { Gerentes técnicos) }\end{array}$ \\
\hline $\begin{array}{l}\text { Instituto de Cardiología } \\
\text { de Corrientes }\end{array}$ & Prestación de servicios médicos & Ley 4087 & $\begin{array}{l}\text { Director Ejecutivo y } 3 \\
\text { Directores técnicos }\end{array}$ \\
\hline $\begin{array}{l}\text { Instituto Correntino del } \\
\text { Agua y del Ambiente }\end{array}$ & $\begin{array}{l}\text { Control y gestión de } \\
\text { los recursos hídricos }\end{array}$ & Decreto Ley $212 / 01$ & $\begin{array}{l}\text { Administrador } \\
\text { General }\end{array}$ \\
\hline $\begin{array}{l}\text { Instituto de Desarrollo } \\
\text { Rural }\end{array}$ & $\begin{array}{l}\text { Promoción del desarrollo } \\
\text { y producción rural }\end{array}$ & Ley 6124 & $\begin{array}{c}\text { Presidente y } 2 \text { vocales } \\
\text { (Ejecutivo) }\end{array}$ \\
\hline $\begin{array}{l}\text { Instituto Provincial del } \\
\text { Tabaco }\end{array}$ & $\begin{array}{c}\text { Promoción y ayuda a } \\
\text { los productores tabacaleros }\end{array}$ & Ley 2338 & $\begin{array}{c}\text { Presidente y Consejo } \\
\text { Directivo ( } 7 \text { miembros } \\
4 \text { por el Ejecutivo, } 3 \\
\text { por las cooperativas } \\
\text { tabacaleras) }\end{array}$ \\
\hline
\end{tabular}

Fuente: Elaboración propia 
Pero la importancia de los entes descentralizados no es solo funcional, sino también económica. De acuerdo a la misma ley de presupuesto, del total de gastos de la provincia para 2016 (\$ 28.275.124.696), los entes descentralizados insumen \$11.604.411.886 (41\% del total). El detalle de los gastos presupuestados para los organismos descentralizados es el siguiente:

Tabla N². Presupuesto 2016 para entes descentralizados en la provincia de Corrientes

\begin{tabular}{|cc|}
\hline Instituto de Previsión Social & 4.879 .313 .992 \\
Instituto de Loterías y Casinos & 2.205 .912 .850 \\
Dirección Provincial de Energía & 1.420 .640 .400 \\
Instituto de la Obra Social de Corrientes & 1.341 .281 .400 \\
Instituto de Vivienda de Corrientes & 1.069 .350 .000 \\
Dirección Provincial de Vialidad & 343.235 .893 \\
Ente Regulador de Aguas & 196.706 .800 \\
Instituto de Cardiología de Corrientes & 110.676 .000 \\
Instituto Correntino del Agua y del Ambiente & 19.000 .802 \\
Instituto de Desarrollo Rural & 12.686 .651 \\
Instituto Provincial del Tabaco & 5.607 .098 \\
Total Entes descentralizados & $\mathbf{1 1 . 5 9 8 . 8 0 4 . 7 8 8}$ \\
\hline
\end{tabular}

Fuente: Elaboración propia en base a ley 6366.

\section{LA INTERVENCIÓN ADMINISTRATIVA}

\subsection{Concepto}

La intervención administrativa es una institución por la que la máxima autoridad administrativa central designa a un funcionario para que regularice una situación de anormalidad que impide el correcto funcionamiento de un ente descentralizado (GORDILLO, 2019 T I, p. 4).

\subsection{Régimen. Funcionario competente para declararla}

La intervención administrativa está prevista en la Constitución de la Provincia de Corrientes $^{8}$ como una atribución del gobernador como titular de la Administración y especialmente regulado en la ley 3460 de procedimiento administrativo. ${ }^{9}$ Es un acto de carácter esencialmente transitorio y excepcional; una potestad propia de la organización administrativa.

\footnotetext{
${ }^{8}$ Constitución de la provincia de Corrientes, Artículo 162: El Gobernador tiene las siguientes atribuciones y deberes:.. 18) Ejerce la fiscalización sobre las reparticiones y organismos autárquicos para asegurar el cumplimiento de los fines respectivos y puede decretar la intervención ad referéndum de la Legislatura.

${ }^{9}$ Ley 3460 artículos 79 al 86. La regulación de la intervención es prácticamente idéntica en la provincia de Salta (Ley 5348 de Procedimiento Administrativo, artículos 20/24) y similar a la de la provincia de Formosa (Decreto Ley 971) art. 25/26 y la provincia de Misiones (Ley I N89 -antes Ley 2970- artículos 16/18).
} 
Marienhoff (1995) señala que la intervención administrativa es un medio de control que no requiere incluso la existencia de una norma que la autorice expresamente, pues ella procede como consecuencia de la potestad de vigilancia que incumbe al órgano superior de la Administración Pública como responsable político de la "administración general".

En el caso de los entes descentralizados, esta potestad de dirección asume la forma de control extraordinario, una "tutela de subrogación" (Dromi, 2009 p. 705).

Si bien la facultad de decretar la intervención corresponde al gobernador, esta potestad es ad referéndum del Poder Legislativo. La ley 3460 establece que el acto que declara la intervención deberá ser motivado y comunicado en el plazo de diez días a la Honorable Legislatura. ${ }^{10}$

Se trata entonces de un acto complejo, que requiere para su perfeccionamiento la concurrencia de la voluntad de la Honorable Legislatura. ¿Cuál es el sentido de esta necesaria ratificación? Se trata de una alteración institucional y de excepción, que afecta el normal funcionamiento de los entes públicos. Esta modificación tiene incidencia presupuestaria y de competencias y por tanto una ampliación del poder, y así como es necesaria una ley formal para crear un ente descentralizado, es necesaria la intervención del Poder Legislativo para dejar sin efecto -al menos transitoriamente- la centralización. Una postura distinta permitiría que el Poder Ejecutivo pueda por un simple decreto dejar sin efecto la centralización decidida por ley formal.

Si luego de decretada la intervención la Legislatura ratifica el acto el acto se perfecciona. ¿Pero qué ocurre cuando no se produce la ratificación legislativa? Pensamos que pueden darse varias situaciones:

-Que la Legislatura rechace expresamente la intervención. En este caso, la intervención debe cesar de modo inmediato, restituyendo a las anteriores autoridades.

-Que la Legislatura no trate el tema (lo que ha ocurrido en todos los antecedentes de intervención que consideramos). En este supuesto, el acto no se perfecciona y se halla viciado de nulidad (Sasson - Saiach, 2016, p.149).

\subsection{Causales de intervención}

La ley enumera como causales de intervención ${ }^{11}$-salvo previsiones en las leyes especiales de creación de los entes- a las siguientes:

a) Suspensión grave e injustificada de la atención o servicio a cargo del ente;

b) Comisión de graves o continuas irregularidades administrativas;

c) Existencia de un conflicto institucional insoluble dentro del ente.

Esta enumeración es taxativa y no pueden invocarse otras para fundar la intervención. No obstante, los términos utilizados, en especial el caso de comisión de graves o continuas irregularidades administrativas posee una amplitud -típica de las normas sancionatorias administrativas - que puede ser utilizada para una variedad de supuestos muy amplios.

\footnotetext{
${ }^{10}$ Ley 3460, artículo 80.

${ }^{11}$ Ley 3460 , artículo 79.
} 
¿Es judiciable la existencia o no de las causales? Consideramos que si bien se trata de una facultad discrecional, el acto de intervención es susceptible -como todo acto administrativode revisión judicial, tanto en sus aspectos reglados (p.e. competencia) como discrecionales (p.e. finalidad, mérito). Sin embargo, el Superior Tribunal de Justicia de Corrientes se ha expedido en sentido contrario - aun cuando se trataba de un órgano desconcentrado- considerando que las razones de oportunidad, mérito y conveniencia que considere el Poder Ejecutivo no son revisables por el Poder Judicial. ${ }^{12}$ Esta solución no tiene fundamento constitucional ni legal, y afecta el principio de tutela judicial efectiva.

\subsection{Potestades del interventor}

El interventor tiene sólo aquellas atribuciones que sean imprescindibles parta solucionar la causa que ha motivado la intervención y asegurar la continuidad jurídica del ente. En ningún caso tiene mayores atribuciones que las que corresponden normalmente a las autoridades superiores del ente. ${ }^{13}$ Dromi (2009, p.705) destaca que, en principio, el interventor solo cumple funciones de mera conservación, no de innovación. En el mismo sentido se ha expedido el Superior Tribunal de Justicia de Corrientes, al rechazar la homologación de un acuerdo suscripto por el interventor de un ente descentralizado. El máximo tribunal provincial sostuvo que:

"El Interventor del Instituto de Lotería y Casinos, como entidad autárquica, es un delegado del Poder Ejecutivo Provincial, quien ha intervenido la institución en merito a los incisos 11 y 18 del art. 162 de la Constitución Provincial, y a la Ley de Ministerios 5549 (Decreto $\mathrm{N}^{\circ}$ 41/o9). Conforme el art. 82 de la ley 3460 el Interventor tiene solo aquellas atribuciones que sean imprescindibles para solucionar la causa que ha motivado la intervención y asegurar la continuidad jurídica del ente. Tal es entonces la regla, y no que el interventor tenga las mismas facultades que el Directorio conforme a la ley 3423". ${ }^{14}$

Los actos del interventor en el desempeño de sus funciones se considerarán realizados por la entidad intervenida. ${ }^{15}$

\subsection{Sustitución de autoridades}

De acuerdo al texto de la ley, la intervención del ente no implica la caducidad de sus autoridades superiores. La separación de éstas de sus funciones, deberá ser resuelta expresamente por el

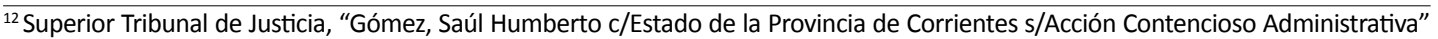
Expte. 1155/9, Sentencia $\mathrm{N}^{\circ} 42$ del 2/06/15.

${ }^{13}$ Ley 3460 , artículo 82.

${ }^{14}$ Superior Tribunal de Justicia, "La Fábrica S.A. c/Instituto de Lotería y Casinos de la Provincia de Corrientes s/Acción Contencioso Administrativa" Expte. 24669/1, Resolución Nº01 del 24/11/11.

${ }^{15}$ Ley 3460 , artículo 83.
} 
Poder Ejecutivo a propuesta del Interventor. ${ }^{16}$ Sin embargo, la práctica administrativa desde 1990 ha sido la de remover a las autoridades del ente en el mismo acto de intervención. Esta práctica es ilegal y no tiene fundamento normativo alguno. Los decretos de intervención han pretendido fundar esta remoción en el artículo 162 inciso 18 de la Constitución provincial o en las normas de emergencia provincial. Sin embargo, la intervención es un acto reglado por la ley 3460 por lo que sus condiciones de validez deben ajustarse a la ley de procedimientos administrativos.

\subsection{Plazo de la intervención}

Por tratarse de un procedimiento de excepción, la intervención debe ser decretada siempre por plazo determinado, que será fijado en la resolución. El máximo legal es de tres meses, prorrogables por otros tres. Si el acto que decreta la intervención no fija el plazo, se entenderá que ha sido establecido el de tres meses. ${ }^{17}$

El objeto de la intervención es siempre restablecer la normalidad de los órganos descentralizados, a fin de asegurar la prestación de los servicios públicos y cualquier clase de actividad estatal (Barraza, 1998). Sin embargo, desde 1993, y salvo el caso del Instituto de Cardiología y de la Dirección Provincial de Vialidad, todos los entes descentralizados permanecen intervenidos a la fecha de este artículo. Esta prolongación en el plazo de las intervenciones y sus consecuencias respecto de la validez de los actos dictados por los interventores serán consideradas en las secciones siguientes.

\subsection{Vencimiento del plazo}

¿Qué ocurre si al vencimiento del plazo de la intervención no se ha normalizado la entidad? La ley 3460 establece que, vencido el plazo de intervención o el de su prórroga, el interventor caducará automáticamente, reasumiendo de pleno derecho sus atribuciones las autoridades superiores de la entidad, que no hubiesen sido separadas del cargo. ${ }^{18}$

Pero ¿Qué sucede si no hay autoridades disponibles para reasumir la conducción del ente? Por principio, la acefalía es una situación no deseada. Por eso la ley prevé que si vencido el plazo de la intervención no hubiera ninguna de las autoridades superiores de la entidad que pueda asumir la administración, el interventor lo hará saber al Poder Ejecutivo y a la H. Legislatura, continuando interinamente en el ejercicio de sus funciones, hasta tanto se resuelva en definitiva la integración de las referidas autoridades. ${ }^{19}$

Sin embargo, este interinato previsto por la ley como una circunstancia transitoria se ha extendido en el tiempo. Así a las primeras intervenciones dispuestas en 1990 para la Dirección

\footnotetext{
${ }^{16}$ Idem.

${ }^{17}$ Ley 3460, artículo 84.

${ }^{18}$ Ley 3460 , artículo 86.

19 Ídem.
} 
Provincial de Energía ${ }^{20}$ y el Instituto de Loterías y Casinos $^{21}$, le siguieron la del Instituto de Obra Social a comienzos de $1992^{22}$ y ya bajo una nueva intervención federal la de todos los otros entes descentralizados. ${ }^{23}$ Reestablecido el orden constitucional provincial en diciembre de 1993, el Poder Ejecutivo, el mismo día de su toma de posesión dictó una nueva intervención para todos los entes descentralizados, ${ }^{24}$ la que con sucesivas prórrogas se mantiene de hecho hasta la fecha de este artículo. ${ }^{25}$ Incluso en las administraciones posteriores a la que finalizó en 1997 -que incluyen a 5 gobernadores electos, 2 gobernadores provisionales y 2 interventores federales- la práctica ha sido la mera designación de nuevos interventores o la ratificación de los existentes, sin mayor preocupación por siquiera prorrogar la intervención original.

Esta prolongación de las intervenciones desnaturaliza el principio de descentralización, y como contrapartida, un aumento de hecho en la esfera de competencias del poder ejecutivo, que pasa a controlar -a través de los interventores- a entes que deberían gozar de autonomía funcional. La situación es aún más irregular, ya que esta desnaturalización de la organización administrativa tiene lugar por decretos del poder ejecutivo y no por una ley formal, ni cumpliendo el trámite de convalidación legislativa prevista en la ley de procedimientos administrativos. En este sentido, es llamativa la pasividad exhibida por el poder legislativo durante este período, en el que no puso en marcha los procedimientos necesarios para el cese de ninguna de las intervenciones administrativas.

\section{CONCLUSIONES}

La descentralización es una técnica de organización del ejercicio poder, cuyas principales ventajas son la constitución de entes altamente especializados, independientes en su gestión de la Administración central y con participación democrática de los interesados. A pesar de la previsión de esta previsión normativa, la Administración central ha utilizado la intervención administrativa como un instrumento para avanzar -sin aval legislativo y sin límite temporalsobre las potestades de los entes descentralizados. De este modo, en los hechos ha conseguido ampliar su propia esfera de poder, más allá de la previsión constitucional.

Existe entonces, un claro divorcio entre la previsión normativa de la intervención administrativa -con motivo en la falta de servicio del ente $u$ otros conflictos graves, sin desplazamiento de sus autoridades, por un plazo breve y al solo efecto de su regularización- y la práctica de los últimos 25 años en la provincia de Corrientes. A lo largo de todo ese período,

\footnotetext{
${ }^{20}$ Decreto $\mathrm{N}^{\circ} 3105 / 1990$.

${ }^{21}$ Decreto $N^{\circ} 235 / 1992$.

${ }^{22}$ Decreto N²35/1992.

${ }^{23}$ Decreto N¹813/1992.

${ }^{24}$ Decreto №13/93 del 10/12/93.

${ }^{25}$ Con las únicas excepciones del Instituto de Cardiología (con sus autoridades normales) y la Dirección Provincial de Vialidad (parcialmente normalizada por Decreto N²331/2011).
} 
la Administración central ha recurrido de manera ordinaria y reiterada a la intervención de las entidades o a la prórroga sine die de las intervenciones ya dispuestas, sin cumplir con los requisitos legales y constitucionales para su procedencia. Una vez decretadas las intervenciones, salvo dos excepciones, se ha omitido todo proceso de regularización o restitución a sus autoridades normales. No obstante lo evidente de estas irregularidades, los actos no han sido cuestionados judicialmente por los excluidos de la conducción de los entes.

Resulta necesario entonces, que, para respetar los límites de la juridicidad, la práctica de las futuras intervenciones administrativas se ajuste a las previsiones constitucionales y legales, utilizándola sola de manera transitoria, en casos de extrema necesidad y con una rápida regularización de los órganos normales de conducción del ente.

Por otro lado, también es conveniente que a la mayor brevedad se inicie el proceso de normalización de las entidades que permanecen intervenidas, en casi todos los casos hace más de dos décadas. De lo contrario, los actos dictados por los funcionarios a cargo de las intervenciones podrán ser impugnados administrativas y judicialmente como nulos o inexistentes jurídicamente (artículo 92 de la ley 3460), con una grave afectación de la seguridad jurídica, y sin perjuicio de la responsabilidad política y administrativa del propio poder ejecutivo por la falta de normalización de los entes.

\section{REFERENCIAS BIBLIOGRÁFICAS}

Balbin, Carlos F. (2011) Tratado de Derecho Administrativo $1^{\text {a }}$ Ed., Buenos Aires, La Ley.

Barraza, Javier Indalecio (1998) "La intervención administrativa y las facultades del interventor", LL 1998-D, p. 187 y ss.).

Cassagne, Juan Carlos (1998) Derecho administrativo, 6ª ed., Buenos Aires, AbeledoPerrot.

Dromi, Roberto (2009) Derecho Administrativo 12 ed. act. Ciudad Argentina - Hispania Libros, Buenos Aires - Madrid - México, 2009.

Gordillo, Agustín (2009) Tratado de Derecho Administrativo Tomo 1, Parte General $10^{\text {a }}$ ed., Buenos Aires, F.D.A.

Marienhoff, Miguel S. (1995), Tratado de derecho administrativo, 5a ed. actualizada, T. I, Buenos Aires, Abeledo Perrot. 
Midón, Mario A. R. (2008) La nueva Constitución de la Corrientes, Corrientes, MAVE.

Sasson, José - Saiach, Samuel N. (2016) Ley de Procedimiento Administrativo de Corrientes, Ley Nro. 346o, Corrientes, Mave.

\section{CURRICULUM VITAE}

\section{Mauricio Goldfarb}

Abogado, UNNE, 1994. Especialista en Derecho Administrativo, UNNE, 2012. Doctorando en Derecho, UNNE, Argentina.

Docente de la Cátedra A de Derecho Administrativo I (Facultad de Derecho, UNNE). estudiogoldfarb@hotmail.com 